\title{
Swyer James Syndrome
}

National Cancer Institute

\section{Source}

National Cancer Institute. Swyer James Syndrome. NCI Thesaurus. Code C85178.

A rare syndrome characterized by the presence of a small lung as a result of unilateral post-infectious bronchiolitis obliterans. 